\title{
BASELINE QUALITY OF LIFE AMONG PATIENTS WITH END STAGE KIDNEY DISEASE IN A RESOURCE LIMITED SETTING
}

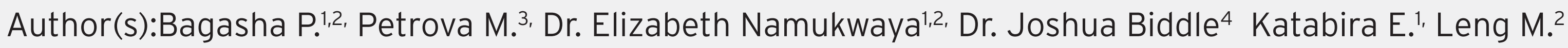

Institute(s): 1. Makerere University College of Health Sciences, School of Medicine, Department of Internal medicine, Kampala, Uganda 2. Makerere and Mulago Palliative Care Unit, Kampala, Uganda, 3. Cambridge Palliative and End of Life Care Research Group, Primary Care Unit, Cambridge University, Department of Public Health and Primary Care, University of Cambridge; Cambridge Institute of Public Health, Forvie Site, Cambridge CB2 OSR, . United Kingdom.mp686@medschl.cam.ac.uk 4 University of California San Francisco

\section{Background}

At $23 \%$ the prevalence of chronic kidney disease in subSaharan Africa is higher than the global prevalence of $16 \%$ With no national healthcare coverage for hemodialysis or kidney transplant, Ugandan patients struggle to pay driving communities into poverty. Studies in developed countries show that patients on hemodialysis may prioritize quality of life (QoL) over survival time. There is a dearth of information about QoL of patients with End Stage Kidney Disease (ESKD) in LMIC.

\section{Aim}

Establish a baseline review of QoL, patient outcomes and associated factors for patients with ESKD receiving hemodialysis versus conservative management in a national referral hospital.

\section{Methods}

A mixed methods analytical study using the Kidney Disease Quality of Life Short Form, African APCA POS and Renal POS. Clinical, demographic and micro-financial information was collected and patient experiences explored using semi-structured interviews.

\section{Results}

38 patients completed with 6 interviewed. $32(84 \%)$ were on hemodialysis and 6 on conservative management. Patients aged from 19 to 78 years with $47 \%$ under 50 years. $68 \%$ were males, $52 \%$ had $>3$ dependants, while $37 \%$ were breadwinners. Majority(81\%) were receiving twice weekly dialysis. On assessment of QoL: $91 \%$ felt kidney disease interfered too much with their life. 37\% felt they were a burden to their family, 61\% felt very frustrated with their lives. Average pain score (POS) was 2.4 with $27 \%$ reporting severe or overwhelming pain. Most had only 1 additional symptom with breathlessness highest prevalence (16\%). Extensive co-morbidities present; $90 \%$ hypertension \& 50\% diabetes
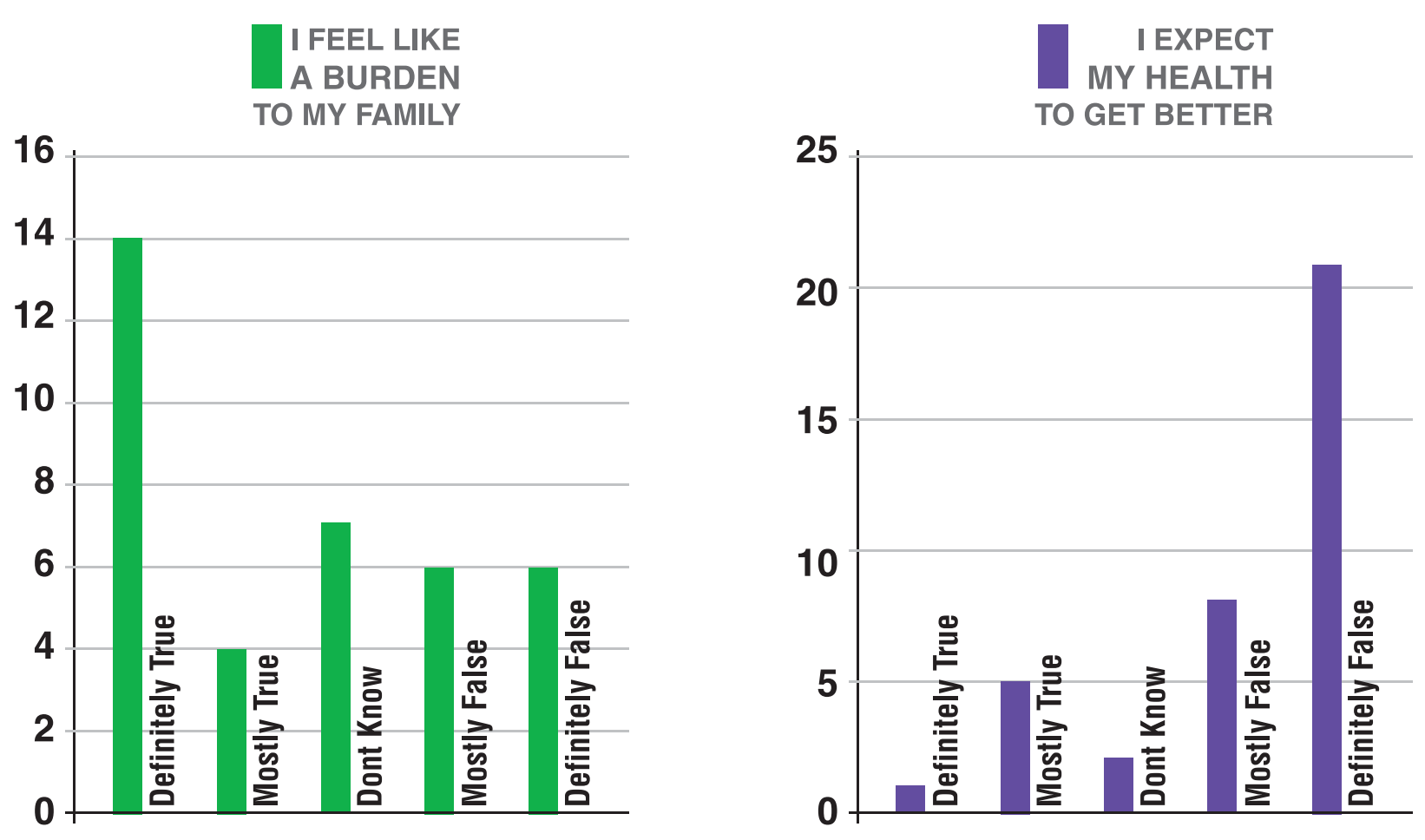

Figure 1: GENERAL HEALTH PERCEPTION

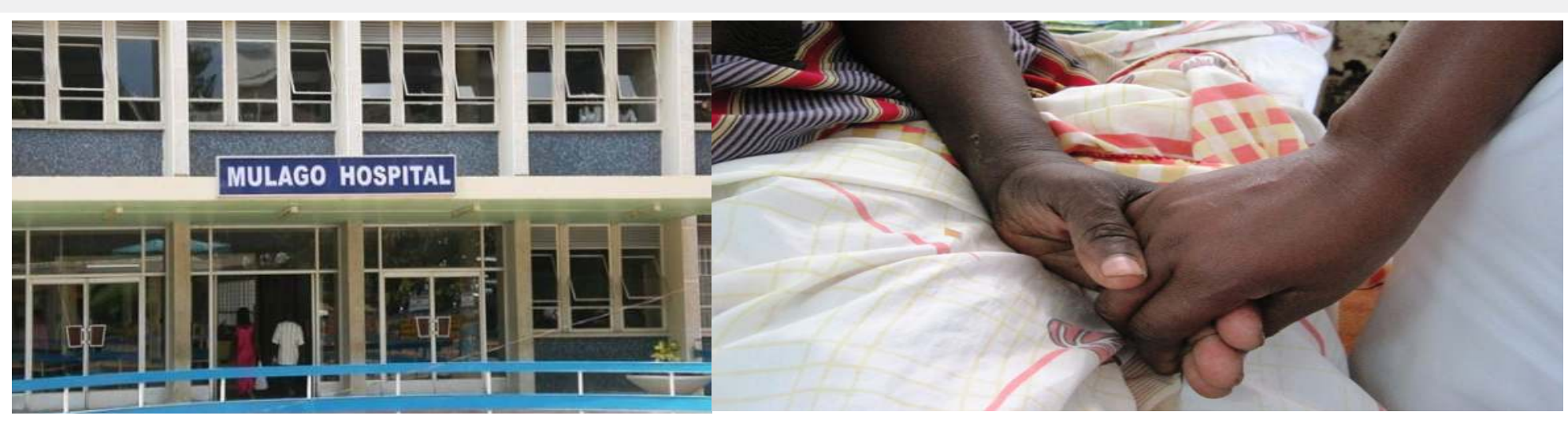

\section{Key themes}

Financial constraints 'I wish God could take me before I deplete my family's resources",

"The Doctor told us that every day has to get an injection and in a week there is that injection he has to get injected the one they inject on the arm ,that medicine costs sixty thousand Ugandan shillings(60,000/-) and the other I buy nineteen thousand Ugandan shillings(19,000/-) when you add on the tablets they do prescribe for him making approximately a total of one hundred thirty thousand Ugandan shillings(130,000/-) every week. Now a farmer like me honestly where can I get that money?"

Disease burden and comorbidities, strong social support systems: "I was working but again I have been down for 2 years so they have been supporting me they are the ones taking care of me I have kids they are the ones taking care of my kids"

"Importance of spirituality: "for me I always keep myself to God so I said let God give the doctors strengthen power to cure this disease",

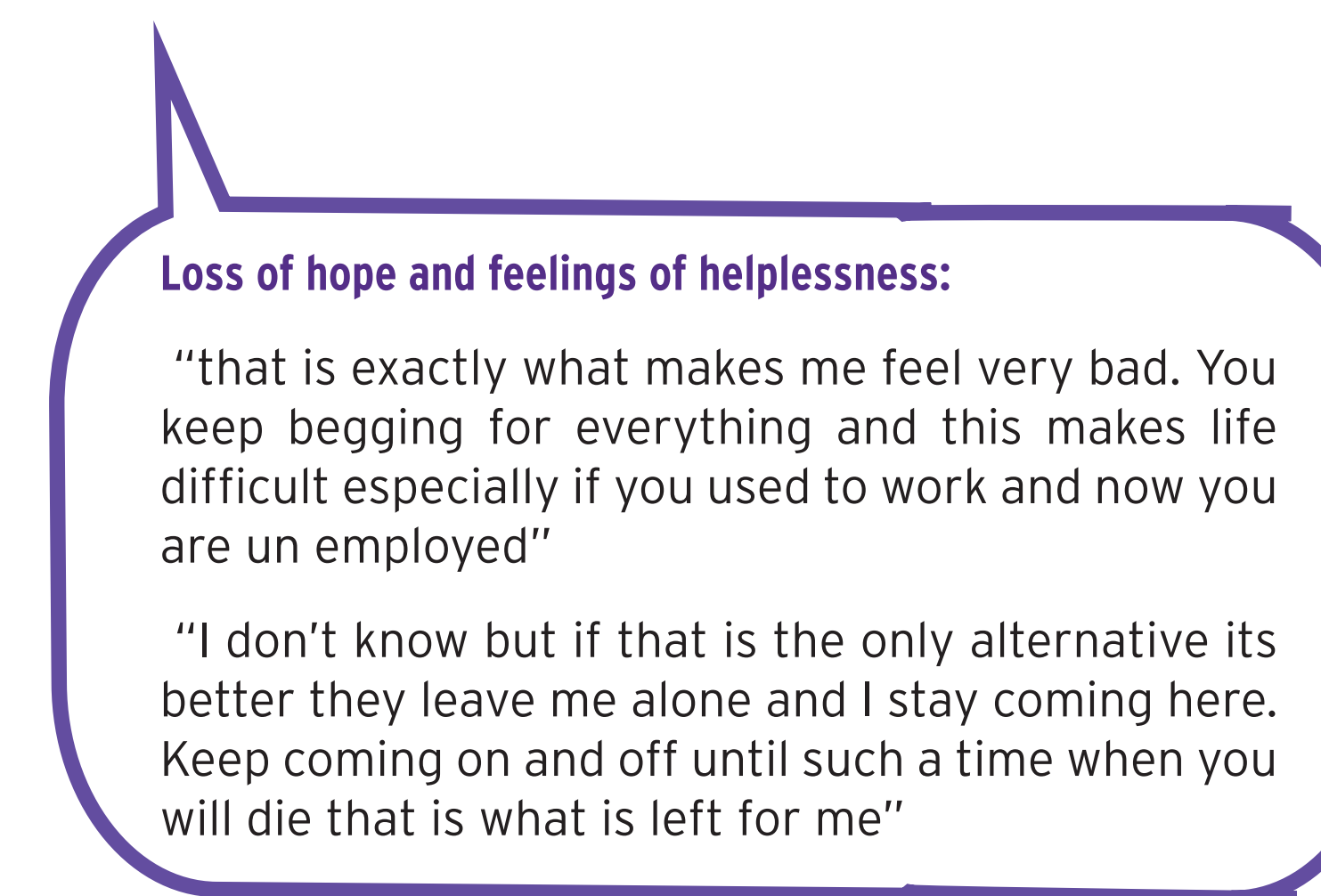

\section{Conclusions}

Improved QoL is a key indicator of successful chronic disease management. This baseline review will inform a wider mixed methods longitudinal study. Improving this evidence base will inform renal and palliative care services with the aim of improving patient experience. 